\title{
Interventions to Promote Colorectal Cancer Screening: An Integrative Review
}

\author{
Susan M. Rawl, PhD, RN, FAAN [Associate Professor], \\ Indiana University School of Nursing, Indianapolis, Indiana, USA
}

Usha Menon, PhD, RN, FAAN [Pamela Kidd Distinguished Research Professor], College of Nursing and Health Innovation, Arizona State University, and the Mayo Clinic Cancer Center, Phoenix, Arizona, USA

Allison Burness, BSN [Cancer Research Training Fellow], and Division of Cancer Control and Population Sciences, National Cancer Institute, Bethesda, Maryland, USA

Erica S. Breslau, PhD [Health Scientist]

Division of Cancer Control and Population Sciences, National Cancer Institute, Bethesda, Maryland, USA

\section{Abstract}

Behavior change interventions to promote colorectal cancer (CRC) screening have targeted people in community and primary care settings, health care providers, and health systems. Randomized controlled trials provide the strongest evidence of intervention efficacy. The purpose of this integrative review was to evaluate trials of CRC screening interventions published between 1997 and 2007 and to identify knowledge gaps and future directions for research. Thirty-three randomized trials that met inclusion criteria were evaluated using a modified version of the TREND criteria. Significant intervention effects were reported in six out of ten trials focused on increasing fecal occult blood testing, four of seven trials focused on sigmoidoscopy or colonoscopy completion, and nine of 16 focused on completion of any screening test. Several effective interventions to promote CRC screening were identified. Future trials need to use theory to guide interventions, examine moderators and mediators, consistently report results, and use comparable outcome measures.

\section{Keywords}

Colorectal cancer; screening; randomized trials; fecal occult blood test; sigmoidoscopy; colonoscopy

C) 2011 Mosby, Inc. All rights reserved.

CORRESPONDENCE TO: Susan M. Rawl, PhD, RN, FAAN, Indiana University School of Nursing, 1111 Middle Drive, NU345-E, Indianapolis, IN, 46202. Telephone: 317-278-2217. srawl@iupui.edu.

Publisher's Disclaimer: This is a PDF file of an unedited manuscript that has been accepted for publication. As a service to our customers we are providing this early version of the manuscript. The manuscript will undergo copyediting, typesetting, and review of the resulting proof before it is published in its final citable form. Please note that during the production process errors may be discovered which could affect the content, and all legal disclaimers that apply to the journal pertain.

Conflict of Interest Statement: The authors have no conflict of interest to disclose. 


\section{INTRODUCTION}

Despite the benefits of early detection and the availability of effective screening tests, colorectal cancer (CRC) remains the third leading cause of cancer death among Americans. The American Cancer Society estimates 1,596,670 new cases and 571,950 deaths from CRC in $2011 .{ }^{1}$ About $90 \%$ of CRC is diagnosed in those age 50 or older and $75 \%$ of cases are diagnosed in people without any known risk factors. ${ }^{2}$ A significant majority of deaths from CRC could be prevented by increasing the use of available screening tests. Tremendous progress has been made to reduce CRC incidence and mortality in recent years, and this progress has been attributed to prevention and early detection achieved through screening. ${ }^{3}$ Continued progress is possible only if we increase access to, and utilization of, CRC screening tests. Currently, only about half of those aged 50 or older have received the recommended tests, with screening rates even lower among those who are less educated or lack insurance. Low rates of CRC screening, coupled with the fact that survival is inversely related to early detection, suggest the continued need for development, testing and translation of interventions to increase screening behavior. This critical need is supported by recommendations of the Oncology Nursing Society, the National Cancer Institute. and remains an objective in the Healthy People 2020 plan. ${ }^{4-6}$ Interventions to increase CRC screening participation have focused on providers, health care systems, and individuals in both clinic and community-based settings. Effective interventions may need to be combined, focused on multiple targets or at multiple levels, and adapted to meet the needs of clients in different settings. Investigators who aspire to design effective interventions to promote CRC screening need to have a clear understanding of, and build upon, existing scientific evidence. The available evidence is presented in this integrative review of recent CRC screening intervention trials.

Numerous professional organizations have published CRC screening recommendations to guide clinical practice over the past two decades. Because recommendations from each organization differed, clinicians and patients were often confused about the most appropriate tests and testing intervals. In 2008, the major professional organizations came together to collaborate on a single set of updated consensus guidelines to promote evidence-based screening practice. ${ }^{7}$ As shown in Table 1 , these new guidelines differentiate tests that primarily detect cancer from those that detect both cancer and adenomatous polyps. This categorization of screening tests is accompanied by greater emphasis on cancer prevention, through removal of precancerous polyps, as the goal of CRC screening.

Because of the number of test options available, measurement of CRC screening outcomes is challenging. Some intervention trials have focused on participation in one specific CRC screening test as the outcome, whereas others have measured participation in any CRC screening test option as the outcome. A critical examination of interventions that have been tested to promote CRC screening will inform the development and design of future intervention trials so that further reductions in morbidity and mortality from this preventable cancer can be realized.

In 1997, Vernon conducted a comprehensive systematic review to evaluate the published literature on adherence to CRC screening with fecal occult blood testing (FOBT) and flexible sigmoidoscopy (FS), including interventions to promote screening. ${ }^{8}$ In 2010 , Holden and colleagues conducted a systematic review to summarize the evidence from interventions that influence CRC screening and strategies that increase the appropriate use and quality of CRC screening in general, rather than specific test use. ${ }^{9}$ Even though these studies report on CRC screening evidence, to our knowledge, our study is the first systematic review to use established criteria to evaluate the quality of published CRC screening intervention trials. The purpose of this integrative review is to advance this 
knowledge by describing CRC screening intervention studies that were published in the decade between 1997 and 2007 and to include trials that have been conducted to promote colonoscopy, an option that has now become the most frequently recommended CRC screening test among providers. ${ }^{10} \mathrm{We}$ further sought to identify gaps in knowledge about increasing screening behaviors by addressing the following aims: 1) Describe efficacious interventions to promote CRC screening; 2) evaluate intervention studies using a modified Transparent Reporting of Evaluations with Nonrandomized Designs (TREND) criteria; and 3 ) discuss the quality of available evidence and implications for future research.

\section{METHODS}

\section{Procedure}

We conducted computer-based searches of several literature databases - PubMed, CINAHL, and Medline/Ovid using the following keywords: colon cancer screening, colorectal cancer screening, interventions, and randomized trials. Over 500 articles were identified, of which 33 met criteria for inclusion in this review. Inclusion criteria were: 1) at least one outcome variable must have focused on CRC screening behavior; 2) at least one intervention designed to increase CRC screening test completion was being tested; 3 ) a randomized trial design was used; and 4) published in English between 1997 and 2007. Only randomized trials were included in this review since our goal was to compare and contrast results of studies that evaluated the efficacy or effectiveness of a behavioral intervention.

Studies were divided into those with FOBT as the outcome ( $\mathrm{n}=10)$, those with FS and/or colonoscopy as the outcome $(\mathrm{n}=7)$, and those with any CRC screening test as the outcome $(\mathrm{n}=16)$. Studies with FS or colonoscopy uptake as outcomes were combined as endoscopic screening. Studies with multiple screening outcomes, that is, more than one screening test, were categorized separately.

Three readers reviewed the studies - approximately 16 articles each. An additional two reviewers assessed a random sample of $10 \%$ of the articles. Agreement on scoring for each article was obtained though discussion until consensus was reached between the two reviewers and three readers. We found variations in coding on four articles, which were then resolved in a phone conference between all authors with reference to the specific sections of the article. We believe that using the standardized, easy to navigate criteria discussed below was largely responsible for the high inter-rater agreement. Criteria for evaluating studies were determined prior to reviewing articles after a comprehensive review and comparison of existing publishing guidelines. We developed a checklist based on the Transparent Reporting of Evaluations with Nonrandomized Designs (TREND) criteria. ${ }^{11}$ In contrast to the CONSORT guidelines for reporting randomized trials, TREND guidelines emphasize more detailed reporting of theories used, descriptions of intervention and comparison conditions, and methods for adjusting for possible biases. Although designed for nonrandomized studies, we decided that modification of the TREND criteria provided the best framework to comprehensively evaluate behavioral intervention trials that promote CRC screening.

Of the original 22-category TREND checklist, we retained 10 major categories consisting of 20 individual criteria that represented critical components of behavioral intervention trials (Tables 6 through 8). The 10 categories were selected based on common design elements for RCTs (randomization, intervention delivery and fidelity, etc) and components emphasized in the CONSORT guidelines. Since the TREND guidelines were published in 2004, over 50\% of the articles selected for review could have used TREND; therefore, all of the TREND components may not be entirely appropriate. Reviewers completed a TREND checklist for each article by indicating "Yes" or "No" with page numbers to specify whether the criterion 
was addressed. Each "Yes" received 1 point and the total score was a sum of the "Yes" responses (See Tables 5, $6 \& 7$ ). Scores ranged from 0 (no criteria met) to 20 (all criteria met). For a criterion to be given a "Yes", that criterion must have been described in the study. Descriptions ranged in the various studies from a brief statement about an issue (e.g., incentives were given to participants) to detailed paragraphs.

\section{RESULTS}

\section{Interventions to Promote Fecal Occult Blood Testing}

Of the 10 randomized trials of interventions to promote FOBT, nine were published since 2000 (Table 2). One study focused on a predominantly male population ${ }^{12}$ and six included minority populations; four focused on African American samples ${ }^{13-16}$ and two on Asian/ Pacific Islanders. ${ }^{17,18}$ Two studies were conducted outside of the U.S. Recruitment settings varied across studies with six trials conducted in primary care settings, two with communitybased samples, and two in work-based settings.

All but one FOBT interventions were delivered at the individual level, directed at primary care patients or people in the community. Interventions included mailed FOBT kits, stool sample collection containers, or invitations to request FOBT kits with letters from primary care practices; ${ }^{13,19,20}$ non-tailored print materials/informational brochures; ${ }^{12,14,16-18,20}$ educational videos; ${ }^{14,16,18}$ computer programs; ${ }^{15}$ group-based educational sessions; $;{ }^{16,17}$ tailored print materials, ${ }^{12}$ as well as culturally targeted print, video and health educatordelivered interventions. ${ }^{16-18}$ The office-based interventions were designed to simplify cancer screening processes for busy primary care practices and included cancer screening checklists, chart stickers, audits, and shared responsibilities for screening among office staff. ${ }^{21}$ Only four of the 10 trials identified specific theories or conceptual frameworks; these included social learning theory ${ }^{17}$, social cognitive theory ${ }^{15}$, the health belief model, the precaution adoption process model, and social comparison theory. ${ }^{12}$ Powe developed her own model to describe relationships between cancer fatalism and screening behavior. ${ }^{16}$

Effective interventions, or positive findings, were reported in six of 10 trials. Interventions resulting in higher FOBT completion rates included: 1) a culturally targeted, nurse-delivered educational program with free FOBT cards, instruction/demonstration, and a reminder call at one month ${ }^{17}$; 2) in-person, home delivery of stool sample collection containers; ${ }^{19}$ 3) mailed FOBT cards with a letter from the provider practice sent to patients two weeks in advance of a visit; ${ }^{13}$ ) a tailored comprehensive print intervention with telephone counseling; ${ }^{12}$ 5) screening education provided by a trilingual, bicultural health educator with languageappropriate video, pamphlets, FOBT cards and instructions; ${ }^{18}$ and 6) a cancer screening office-based system intervention that included screening checklists, chart stickers, audits and shared responsibilities for screening among office staff. ${ }^{21}$ Some trials reported intervention effects that were different for certain subgroups. An informational brochure accompanied by a letter from the medical practice offering free FOBT was more effective than a letter alone for men, but not for women. ${ }^{20}$

Two studies reported negative findings because the comparison group(s) received equally effective interventions. Providing an educational video to patients waiting to see their providers did not increase FOBT completion rates beyond rates achieved with an ACS screening brochure plus a note card for patients to give to the provider to order an FOBT. ${ }^{14}$ Similarly, a computerized educational program did not outperform a nurse providing one-toone instruction on completing FOBT. ${ }^{15}$ With one exception, all studies examined one-time FOBT completion as the primary outcome, rather than annual, or repeat, screening. Lipkus and colleagues examined initial, yearly, and repeat FOBT in their four-group longitudinal 
trial comparing basic and comprehensive print interventions with tailored and non-tailored messages. $^{12}$

In summary, $60 \%$ of the studies that assessed FOBT as the outcome showed significant intervention effects; 5 studies that tested patient-directed interventions and 1 testing a system/provider intervention.

\section{Interventions to Promote Screening Endoscopy}

Of the seven trials of interventions to promote FS and colonoscopy, publication dates ranged from 1999 to 2004 (Table 3). Settings for these studies were mainly primary care with one study in neighborhood community clinics. ${ }^{22}$ One study was conducted outside the U.S., in Scotland. ${ }^{23}$ The majority of interventions were targeted to patients, with only one study focused on providers. ${ }^{24}$ Theoretical frameworks guiding the interventions were not reported in three studies; ${ }^{22,23,25}$ those reporting frameworks used a combination of popular behavior change models with the most popular being the Health Belief Model. Interventions ranged from targeted informational letters or brochures ${ }^{23,25,26}$ to videos or phone counseling 27,28 to provider seminars/lectures. ${ }^{24,29}$

In the majority of these trials, the targeted outcome was FS completion with only three studies focused on colonoscopy. ${ }^{24,25,28}$ Differences in how screening completion was reported - from actual percent completing the test, to percent increase from baseline, to odds ratios - make comparisons across the seven studies problematic. Significant effects were reported in two studies on $\mathrm{FS}^{26,27}$ and two studies on colonoscopy. ${ }^{25,28}$ One study found significant intervention effects on the outcome of a complete diagnostic evaluation defined as a colonoscopy or combined FS plus barium enema X-ray. ${ }^{30}$ Successful interventions reported were: 15 -minute videos mailed to participants' homes, ${ }^{27}$ mailed health information booklet, ${ }^{26}$ and usual care plus an informational brochure. ${ }^{25}$ In comparing motivational interviewing versus mailed brochures to usual care, significantly lower use of colonoscopy was observed in the usual care group; however no differences were found between intervention arms. ${ }^{28}$ The only physician-directed education also found significant increases in complete diagnostic evaluation post-intervention. ${ }^{30}$

Intervention effects were not significant in two studies. The first compared an invitation to have a FS with an explanatory leaflet to a similar invitation and leaflet plus the option to discuss screening with a physician. ${ }^{22}$ The second intervention comprised a comprehensive pre-education baseline survey of provider attitudes and practice patterns, a didactic seminar on the current status of screening, implementation of on-site FS services, procedural training for interested providers, and the establishment of a free-standing FS screening program staffed by primary care providers. This was compared to didactic seminars only. ${ }^{29}$

In summary, $80 \%$ of studies that assessed endoscopy as the outcome showed significant intervention effects. Colonoscopy was the outcome in 3 of 7 studies. Interventions with significant effects were all directed at patients.

\section{Interventions to Promote Any CRC Screening Test}

Of the 16 reviewed randomized trials testing interventions to promote more than one CRC screening test, all but two were published after 2002 (Table 4). Five trials focused on minority populations; three recruited African Americans ${ }^{31,32}$ and two enrolled Hispanics. ${ }^{33,34}$ Ten trials were conducted with patient populations in primary care settings or health maintenance organizations, and six in community-based settings. One study conducted in Italy enrolled both general practice patients and members of the general population. ${ }^{35}$ 
All 16 trials tested interventions that were directed at the individual level to individual patients, employees, or community members. Three studies combined patient-directed interventions with health care system (provider or practice-directed) interventions. ${ }^{36-38}$ Types of patient-directed interventions included non-tailored print materials/informational brochures, ${ }^{30,33,35-37,39,40}$ tailored print materials, ${ }^{30,32,40,41}$ tailored telephone counseling, ${ }^{31,33,39,41}$ targeted videos, ${ }^{32,42}$ interactive computer programs, ${ }^{43,44}$ mailed FOBT kits, ${ }^{30,33,35,36,45}$ lay health advisors, ${ }^{32}$ prevention care managers, ${ }^{33}$ or patient navigators. ${ }^{34}$ Provider or practice-directed interventions included academic detailing, ${ }^{36}$ systems for tracking overdue patients, ${ }^{38}$ expanding office staff responsibilities for screening, ${ }^{38}$ educational workshops, ${ }^{37}$ performance feedback, and/or other types of quality improvement initiatives ${ }^{36-38}$ Eight of the 16 trials used a specific health behavior theory including: the health belief model, ${ }^{32,40,41}$ transtheoretical model, $32,40,42$ social cognitive theory, ${ }^{32,41}$ precaution adoption process model, ${ }^{39}$ analytic hierarchy process multicriteria decision theory, ${ }^{43}$ preventive health model, ${ }^{30}$ elaboration likelihood model, ${ }^{44}$ theory of planned behavior, ${ }^{41}$ and social support models ${ }^{32}$. Two studies used multiple health behavior theories but did not specify which were used. ${ }^{31,45}$

Significant intervention effects were reported in 9 of 16 trials. Effective interventions included: 1) tailored telephone counseling; ${ }^{31}$ 2) non-tailored brochure plus telephone support calls from a prevention care manager; ${ }^{33} 3$ ) targeted video with non-tailored print information combined with a provider-directed education, performance feedback, and a quality improvement intervention; ${ }^{37} 4$ ) an ethnically-matched patient navigator; ${ }^{34}$ 5) a brief educational message with multiple mailings of tailored print materials; ${ }^{40} 6$ ) tailored and non-tailored print materials mailed with FIT kit and 30-day reminders; ${ }^{30} 7$ ) an interactive web-based computer program designed to establish user preferences for $\mathrm{CRCS}^{44} 8$ ) an annual mailed screening invitation with tailored education booklet plus follow-up phone call; ${ }^{41}$ and 9) an academic detailing intervention combined with a letter from the provider, an educational brochure, and FOBT kit with instructions. ${ }^{36}$ In two studies, subgroup analyses based on exposure to the intervention yielded significant results. ${ }^{32,39}$ In a study testing both single and multiple mailings of tailored and non-tailored print materials with callers to the Cancer Information Service, intervention effects were moderated by age, gender, and prior screening history. ${ }^{40}$

Negative findings were reported in six trials. ${ }^{32}$ In one study, FOBT adherence rates for two intervention groups that received mailed FOBT kits, with or without reminders, were $18 \%$ higher than rates for controls, but no significance tests were reported. ${ }^{45}$ Similar to the FOBT trials, all but two studies examined one-time, as opposed to repeat, screening. ${ }^{38,41}$

In summary, $60 \%$ of the studies reviewed had significant intervention effects. Of these 9 studies, two were testing some component of system change/provider education while the remaining 7 tested patient-directed interventions.

\section{Evaluation of FOBT Intervention Trials Using TREND Criteria}

The ten studies with FOBT participation or adherence as the primary outcome were evaluated against TREND criteria (Table 5). In general, most studies met intervention reporting criteria. All 10 trials described the study design; stated specific aims, goals or hypotheses; clearly defined outcomes; described eligibility criteria; provided details of the intervention(s) for each condition; described the intervention delivery method and setting; and included negative study findings. No studies met all 20 criteria primarily because none of the 10 trials had described activities to increase adherence (incentives); this is possibly because incentives were not used. Four trials met the remaining 19 (95\%) criteria because they were the only studies that described the conceptual framework or theory used. 


\section{Evaluation of Endoscopy Intervention Trials Using Modified TREND criteria}

The evaluation of endoscopy intervention studies is presented in Table 6. Overall, most studies met intervention reporting criteria. Outcome variables were defined in all studies. Two criteria - theoretical frameworks and activities to increase adherence (incentives) were met by very few studies. Research to increase endoscopic screening has several strengths. The majority of studies had clearly defined outcome variables, intervention content and procedures were described and generalizability and interpretation of findings in the context of current knowledge were discussed. Limitations of research in this area were related to lack of theoretical frameworks and information about incentives given to participants. Three interventions did not have significant effects. Those reporting odds ratios had small to moderate effects. A primary limitation, however, is related to the lack of standardized reporting of effects. Results of interventions were reported as percent increases ${ }^{25}$ to odds ratios, ${ }^{30}$ making comparisons of the effectiveness of interventions across studies difficult.

\section{Evaluation of Intervention Trials to Promote Any CRC Screening Using TREND Criteria}

The 16 studies with any CRC screening adherence as the primary outcome were also evaluated using the TREND criteria (Table 7). Overall, most studies met intervention reporting criteria. All 16 trials met four criteria; investigators clearly defined the outcomes, described the settings and locations where data were collected, and provided details of intervention delivery method and the unit of delivery. Thirteen $(81 \%)$ trials met 17 out of the 20 criteria. Although the use of theory was slightly higher than in trials of interventions to promote FOBT alone (40\%), only 10 (62\%) trials used conceptual frameworks or theories to design interventions. Criteria met by the fewest trials included descriptions of activities to increase adherence (incentives) $(n=5)$, eligibility criteria $(n=12)$, and who delivered the intervention $(n=12)$.

\section{DISCUSSION}

We sought to update the behavioral intervention literature on CRC screening since 1997. In the decade from 1997 to 2007, significant progress was made in developing innovative and effective interventions to promote CRC screening. Though early studies focused on individual CRC screening tests, such as FOBT or FS separately, more recent studies have addressed the complexity of CRC screening by examining completion of multiple test options, including colonoscopy. The inclusion of colonoscopy as an outcome reflects the increased utilization of that test for both screening and diagnostic purposes. Because the completion of a colonoscopy negates the need for annual FOBT and FS, the interdependence of these screening tests cannot be ignored. As a result, the majority of recent intervention trials examined multiple test outcomes.

In a comprehensive review of $23 \mathrm{CRC}$ screening intervention studies published prior to 1997, Vernon reported on 18 studies focused on increasing adherence to FOBT; four designed to increase FS; and one on colonoscopy. ${ }^{8}$ Five studies used behavior change theories or models in developing interventions. In contrast, almost half, 16 of 33 studies reviewed here used such a theory or model. Theories guide selection of intervention components, study design, sampling, and appropriate outcomes. ${ }^{46}$ Theories allow investigators to specify the mechanisms of action of interventions and identify potential mediators. Without theory-based interventions, it is not possible to deconstruct intervention effects, to attribute outcomes to specific components, or to understand why an intervention was or was not effective. It is encouraging to note that a greater proportion of recent interventions are theory-based, but continued advancement in the refinement and application of theories that better explain CRC screening behavior is needed. 
Effective interventions, reported in 19 of 33 trials, included culturally-matched in-person education and counseling, tailored print materials with and without telephone counseling, mailed informational brochures with letters/invitations from providers and FOBT cards, mailed videos, tailored phone counseling, and an interactive web-based computer program. Several provider or system interventions were effective especially when combined with the foregoing patient-directed interventions. Such interventions included academic detailing, screening reminders and prompts, audits, feedback and shared responsibility for CRC screening. Our findings are consistent with a recent review that graded the strength of the available evidence for CRC screening interventions. ${ }^{9}$ These investigators considered the strength of the evidence to be high for interventions that reduced structural barriers to CRC screening, including one-on-one interactions, patient reminders, and small media without decision aids. Our results also support the need for interventions that eliminate structural and system-level barriers, especially those that include patient reminders or one-on-one interactions and that aim at making the screening process easier, especially for target populations. ${ }^{9}$

The CRC screening intervention trials reviewed here had numerous strengths, yet their limitations make it difficult to draw definitive conclusions about studies. Though the TREND criteria include reporting of negative findings, standardized reporting of results with appropriate statistical testing is not a criterion. Comparisons across studies would be enhanced if results had consistent statistical reporting. Many studies reported negative findings because the control or comparison condition was, in itself, an effective intervention. The current movement to conduct practical clinical trials and comparative effectiveness studies will likely result in increasing numbers of these types of study designs.

It was interesting to note that none of the trials evaluated met the TREND criterion related to describing activities to increase compliance or adherence, including incentives. While it is possible that no incentives were offered in any of these studies, the use of incentives to thank participants for their time and effort is quite common. Disclosure of such information is essential in reporting intervention trials since incentives have potential to influence behavioral outcomes such as CRC screening.

Few trials have examined adherence to annual (repeat) FOBT, but rather, most focused on one-time FOBT. The effectiveness of this CRC screening test is dependent on adherence to annual testing and this review does not enhance our understanding of effective interventions to promote repeat testing. A number of trials included people who were already adherent or up-to-date with CRC screening. Delivering interventions to individuals who do not need them not only wastes limited resources but also makes interpretation of results challenging.

Understanding for whom interventions are most and least effective is important but often goes unreported. Few trials examined moderators of intervention effects. Hart $^{20}$ reported that an informational brochure accompanied by a letter from medical practice offering free FOBT was more effective than a letter alone for men, but not for women. In two studies, degree of exposure (intervention dose) moderated effects of the intervention. ${ }^{32,39}$ Campbell and colleagues found that, among participants who received four computer-tailored newsletters with targeted videotapes over a 9 month period, a higher proportion of those who read the newsletters completed FOBT compared to those who did not (35\% vs. $12 \%$, $\mathrm{p}<0.01$ ). Similarly, among those who received a lay health advisor intervention, more people who spoke directly with the lay health advisor completed FOBT ( $48 \%$ vs. $26 \%, \mathrm{p}<0.01)$. Costanza, et. al. reported that when they compared participants who received the tailored telephone counseling call with those who did not, a significant difference in adherence to any CRC screening test was observed $(\mathrm{p}<0.0001) .{ }^{39}$ In a study testing both single and multiple mailings of tailored and non-tailored print materials with callers to the Cancer 
Information Service, intervention effects were moderated by age, gender, and prior screening history. ${ }^{40}$

Another notable limitation in this body of research is the inadequate inclusion of minority participants. Given the rapidly changing demographics in the U.S., with Latinos expected to reach $25 \%$ of the overall population, ${ }^{47}$ it becomes imperative that adequate numbers of diverse participants are enrolled in studies to permit meaningful comparisons of intervention effects by race/ethnicity. Cancer screening disparities remain a considerable burden among certain racial/ethnic groups, particularly among those who receive a late-stage diagnosis leading to lower survival rates. ${ }^{48}$

Until recently, screening trials conducted in ethnically-diverse populations have relied on traditional models of behavior change such as the health belief model or social cognitive theory. Such models propose that increasing knowledge leads to behavior change and their application has led to widespread use of individually-focused, cognitively-based interventions. These theories and the interventions built on them do not consider cultural beliefs or the socio-cultural contexts that influence health behavior. Health care experiences and beliefs that are shaped from childhood - about causes of illness and perceptions of the body - need to be explored within the social context if we are to understand their influence on CRC screening behavior. ${ }^{49,50}$ Religious or spiritual orientation, which varies by country of origin and is prominent among many African-American groups, has received limited attention despite being related to cancer screening. ${ }^{51}$ Including meaningful numbers of diverse participants in studies, increasing our understanding of the social contexts in which people and providers make decisions about CRC screening, and learning how to leverage culture to optimize intervention effects ${ }^{51}$ may well turn the tide in the ongoing struggle to increase CRC screening rates.

\section{Strengths and Limitations}

To our knowledge, this is the first systematic review to use established criteria to evaluate the quality of published CRC screening intervention trials. Though we examined several recognized standards for reporting results of clinical trials, the TREND criteria were the most comprehensive and relevant for these types of interventions. It must be noted, however, that many of the articles reviewed were published prior to establishment of the TREND criteria in 2004. Publication bias that resulted in selective reporting of positive trials may have influenced our results and conclusions. In light of the substantial number of studies identified with negative findings, this is not considered to be a serious limitation. Despite use of comprehensive search strategies, it is possible that some trials were missed or inappropriately excluded.

\section{Recommendations for Future Research}

In many healthcare settings, system and patient-centered interventions have been put in place as evidence has accumulated. Health care reform is underway with a major emphasis on expansion of primary care services. Our ability to translate effective interventions into clinical or public health practice will require greater attention to the cost-effectiveness of interventions and the conduct of trials that move beyond efficacy. Given the mix of findings, a priority for future research should be to encourage comparative effectiveness research to understand which strategies work best with specific populations, and provide the greatest benefit in increasing CRC screening. Strategies to expedite translation of effective cancer screening interventions include: 1) greater attention to multilevel interventions that take the social contexts of CRC screening behavior into account; 2) more consistent reporting of results of intervention trials; 3 ) more extensive use of theory to guide intervention development; 4) examination of mediators and moderators to explain the mechanism of 
intervention effects; and 5) use of research designs other than randomized trials to conduct implementation research. ${ }^{52}$ Moving effective, culturally-appropriate, and sustainable interventions into practice is the necessary next step to eliminate health disparities and further reduce the burden of CRC for all.

\section{Acknowledgments}

We gratefully acknowledge Phyllis Dexter, PhD, RN, Kimberly Mitchell, PhD, RN, Michelle Symms Juan, MS, RN, Laura Ladd Vodola, BSN., and Darlene Deer for their review and assistance with this manuscript.

\section{REFERENCES}

1. American Cancer Society. Cancer Facts \& Figures 2011. Atlanta: American Cancer Society; 2011.

2. National Cancer Institute. Colorectal Cancer Progress Review Group. 2000. Conquering colorectal cancer: A blueprint for the future.

3. American Cancer Society. Colorectal Cancer Facts \& Figures 2008- 2010. Atlanta: American Cancer Society; 2008.

4. Berger AM, Cochrane B, Mitchell SA. The 2009-2013 research agenda for oncology nursing. Oncol Nurs Forum. 2009; 36:E274-E282. [PubMed: 19726387]

5. Meissner HI, Breen N, Klabunde CN, Vernon SW. Patterns of colorectal cancer screening uptake among men and women in the United States. Cancer Epidemiol Biomarkers Prev. 2006; 15:389394. [PubMed: 16492934]

6. Services USDoHaH. Healthy People 2020 plan. 2010 In;

7. Levin B, Lieberman DA, McFarland B, et al. Screening and surveillance for the early detection of colorectal cancer and adenomatous polyps, 2008: a joint guideline from the American Cancer Society, the US Multi-Society Task Force on Colorectal Cancer, and the American College of Radiology. CA Cancer J Clin. 2008; 58:130-160. [PubMed: 18322143]

8. Vernon SW. Participation in colorectal cancer screening: a review. J Natl Cancer Inst. 1997; 89:1406-1422. [PubMed: 9326910]

9. Holden DJ, Jonas DE, Porterfield DS, Reuland D, Harris R. Systematic review: enhancing the use and quality of colorectal cancer screening. Ann Intern Med. 152:668-676. [PubMed: 20388703]

10. Klabunde CN, Ambs A, Keating NL, et al. The role of primary care physicians in cancer care. J Gen Intern Med. 2009; 24:1029-1036. [PubMed: 19597893]

11. Des Jarlais DC, Lyles C, Crepaz N. Improving the reporting quality of nonrandomized evaluations of behavioral and public health interventions: the TREND statement. Am J Public Health. 2004; 94:361-366. [PubMed: 14998794]

12. Lipkus IM, Skinner CS, Dement J, et al. Increasing colorectal cancer screening among individuals in the carpentry trade: test of risk communication interventions. Prev Med. 2005; 40:489-501. [PubMed: 15749130]

13. Goldberg D, Schiff G, McNutt R, Furumoto-Dawson A, Hammerman M, Hoffman A, Abcarian H. Mailings timed to patients' appointments. A controlled trial of fecal occult blood test cards. Am J Prev Med. 2004; 26:431-435. [PubMed: 15165660]

14. Friedman LC, Everett TE, Peterson L, Ogbonnaya KI, Mendizabal V. Compliance with fecal occult blood test screening among low-income medical outpatients: a randomized controlled trial using a videotaped intervention. J Cancer Educ. 2001; 16:85-88. [PubMed: 11440068]

15. Miller DP Jr, Kimberly JR Jr, Case LD, Wofford JL. Using a computer to teach patients about fecal occult blood screening. A randomized trial.[see comment]. Journal of General Internal Medicine. 2005; 20:984-988. [PubMed: 16307621]

16. Powe BD, Ntekop E, Barron M. An intervention study to increase colorectal cancer knowledge and screening among community elders. Public Health Nursing. 2004; 21:435-442. [PubMed: 15363024]

17. Braun KL, Fong M, Kaanoi ME, Kamaka ML, Gotay CC. Testing a culturally appropriate, theorybased intervention to improve colorectal cancer screening among Native Hawaiians. Prev Med. 2005; 40:619-627. [PubMed: 15850857] 
18. Tu SP, Taylor V, Yasui Y, et al. Promoting culturally appropriate colorectal cancer screening through a health educator: a randomized controlled trial. Cancer. 2006; 107:959-966. [PubMed: 16865681]

19. Courtier R, Casamitjana M, Macia F, et al. Participation in a colorectal cancer screening programme: influence of the method of contacting the target population. Eur J Cancer Prev. 2002; 11:209-213. [PubMed: 12131653]

20. Hart AR, Barone TL, Gay SP, et al. The effect on compliance of a health education leaflet in colorectal cancer screening in general practice in central England. Journal of Epidemiology \& Community Health. 1997; 51:187-191. [PubMed: 9196650]

21. Roetzheim RG, Christman LK, Jacobsen PB, et al. A randomized controlled trial to increase cancer screening among attendees of community health centers. Ann Fam Med. 2004; 2:294-300. [PubMed: 15335126]

22. Schroy PC. Factors affecting provider use of screening sigmoidoscopy identified. Gastroenterology. 1999; 117:304-311. [PubMed: 10419910]

23. Gray M, Pennington CR. Screening sigmoidoscopy: a randomised trial of invitation style. Health Bull (Edinb). 2000; 58:137-140. [PubMed: 12813842]

24. Myers RE, Turner B, Weinberg D, et al. Impact of a physician-oriented intervention on follow-up in colorectal cancer screening. Preventive Medicine. 2004; 38:375-381. [PubMed: 15020170]

25. Denberg TD, Coombes JM, Byers TE, et al. Effect of a mailed brochure on appointment-keeping for screening colonoscopy: a randomized trial. Annals of Internal Medicine. 2006; 145:895-900. [PubMed: 17179058]

26. Wardle J, Williamson S, McCaffery K, et al. Increasing Attendance at Colorectal Cancer Screening: Testing the Efficacy of Mailed, Psychoeducational Intervention in a Community Sample of Older Adults. Health Psychology. 2003; 22:99-105. [PubMed: 12558207]

27. Zapka JG, Lemon SC, Puleo E, Estabrook B, Luckmann R, Erban S. Patient education for colon cancer screening: a randomized trial of a video mailed before a physical examination. Ann Intern Med. 2004; 141:683-692. [PubMed: 15520425]

28. Turner BJ, Weiner M, Berry SD, Lillie K, Fosnocht K, Hollenbeak CS. Overcoming poor attendance to first scheduled colonoscopy: a randomized trial of peer coach or brochure support. J Gen Intern Med. 2008; 23:58-63. [PubMed: 18030540]

29. Schroy PC, Heeren T, Bliss CM, Pincus J, Wilson S, Prout M. Implementation of on-site screening sigmoidoscopy positively influences utilization by primary care providers. Gastroenterology. 1999; 117:304-311. [PubMed: 10419910]

30. Myers RE, Sifri R, Hyslop T, et al. A randomized controlled trial of the impact of targeted and tailored interventions on colorectal cancer screening. Cancer. 2007; 110:2083-2091. [PubMed: 17893869]

31. Basch CE, Wolf RL, Brouse CH, et al. Telephone Outreach to Increase Colorectal Cancer Screening in an Urban Minority Population. American Journal of Public Health. 2006; 96:22462253. [PubMed: 17077394]

32. Campbell MK, James A, Hudson MA, et al. Improving multiple behaviors for colorectal cancer prevention among African American church members. Health Psychology. 2004; 23:492-502. [PubMed: 15367069]

33. Dietrich AJ, Tobin JN, Cassells A, et al. Telephone care management to improve cancer screening among low-income women: a randomized, controlled trial. Annals of Internal Medicine. 2006; 144:563-571. [PubMed: 16618953]

34. Jandorf L, Gutierrez Y, Lopez J, Christie J, Itzkowitz SH. Use of a patient navigator to increase colorectal cancer screening in an urban neighborhood health clinic. Journal of Urban Health. 2005; 82:216-224. [PubMed: 15888638]

35. Segnan N, Senore C, Andreoni B, et al. Randomized trial of different screening strategies for colorectal cancer: patient response and detection rates. J Natl Cancer Inst. 2005; 97:347-357. [PubMed: 15741571]

36. Walsh JM, Salazar R, Terdiman JP, Gildengorin G, Perez-Stable EJ. Promoting use of colorectal cancer screening tests. Can we change physician behavior? J Gen Intern Med. 2005; 20:10971101. [PubMed: 16423097] 
37. Ferreira MR, Dolan NC, Fitzgibbon ML, et al. Health care provider-directed intervention to increase colorectal cancer screening among veterans: results of a randomized controlled trial. J Clin Oncol. 2005; 23:1548-1554. [PubMed: 15735130]

38. Ruffin, MTt; Gorenflo, DW. Interventions fail to increase cancer screening rates in communitybased primary care practices. Prev Med. 2004; 39:435-440. [PubMed: 15313081]

39. Costanza ME, Luckmann R, Stoddard AM, et al. Using tailored telephone counseling to accelerate the adoption of colorectal cancer screening. Cancer Detect Prev. 2007; 31:191-198. [PubMed: 17646058]

40. Marcus AC, Mason M, Wolfe P, et al. The efficacy of tailored print materials in promoting colorectal cancer screening: results from a randomized trial involving callers to the National Cancer Institute's Cancer Information Service. J Health Commun. 2005; 10(Suppl 1):83-104. [PubMed: 16377602]

41. Tilley BC, Vernon SW, Myers R, et al. The Next Step Trial: impact of a worksite colorectal cancer screening promotion program. Preventive Medicine. 1999; 28:276-283. [PubMed: 10072746]

42. Pignone M, Harris R, Kinsinger L. Videotape-based decision aid for colon cancer screening. A randomized, controlled trial. Annals of Internal Medicine. 2000; 133:761-769. [PubMed: 11085838]

43. Dolan JG, Frisina S. Randomized controlled trial of a patient decision aid for colorectal cancer screening. Medical Decision Making. 2002; 22:125-139. [PubMed: 11958495]

44. Ruffin, MTt; Fetters, MD.; Jimbo, M. Preference-based electronic decision aid to promote colorectal cancer screening: results of a randomized controlled trial. Prev Med. 2007; 45:267-273. [PubMed: 17689600]

45. Church TR, Yeazel MW, Jones RM, et al. A randomized trial of direct mailing of fecal occult blood tests to increase colorectal cancer screening. J Natl Cancer Inst. 2004; 96:770-780. [PubMed: 15150305]

46. Pingree S, Hawkins R, Baker T, duBenske L, Roberts LJ, Gustafson DH. The value of theory for enhancing and understanding e-health interventions. Am J Prev Med. 38:103-109. [PubMed: 20117565]

47. Day, JC. Population Projections of the United States by AGe, Sex, Race, and Hispanic Origin: 1995 to 2050. Washington, DC: 1996.

48. Jemal A, Siegel R, Ward E, Hao Y, Xu J, Thun MJ. Cancer statistics, 2009. CA Cancer J Clin. 2009; 59:225-249. [PubMed: 19474385]

49. Pasick RJ, Burke NJ. A critical review of theory in breast cancer screening promotion across cultures. Annu Rev Public Health. 2008; 29:351-368. [PubMed: 17914932]

50. Burke NJ, Joseph G, Pasick RJ, Barker JC. Theorizing social context: rethinking behavioral theory. Health Educ Behav. 2009; 36:55S-70S. [PubMed: 19805791]

51. Fisher TL, Burnet DL, Huang ES, Chin MH, Cagney KA. Cultural leverage: interventions using culture to narrow racial disparities in health care. Medical Care Research \& Review. 2007; 64:243S-282S. [PubMed: 17881628]

52. Glasgow RE, Marcus AC, Bull SS, Wilson KM. Disseminating effective cancer screening interventions. Cancer. 2004; 101:1239-1250. [PubMed: 15316911]

53. Roetzheim RG, Christman LK, Jacobsen PB, Schroeder J, Abdulla R, Hunter S. Long-term results from a randomized controlled trial to increase cancer screening among attendees of community health centers. Ann Fam Med. 2005; 3:109-114. [PubMed: 15798035]

54. Hart AR, Barone TL, Mayberry JF. Increasing compliance with colorectal cancer screening: the development of effective health education. Health Education Research. 1997; 12:171-180. [PubMed: 10168571] 


\section{Table 1}

Guidelines for Colorectal Cancer Screening: $2008^{(4)}$

\begin{tabular}{|l|l|}
\hline Tests that detect both cancer and polyps & Tests that primarily detect cancer \\
\hline $\begin{array}{l}\text { Flexible sigmoidoscopy every } 5 \text { years } \\
\text { Colonoscopy every } 10 \text { years }\end{array}$ & Guiac-based fecal occult blood test every year \\
$\begin{array}{l}\text { Double contrast barium enema every } 5 \text { years } \\
\text { CT (virtual) colonography every } 5 \text { yrs }\end{array}$ & Fecal immunochemical test every year \\
\hline
\end{tabular}




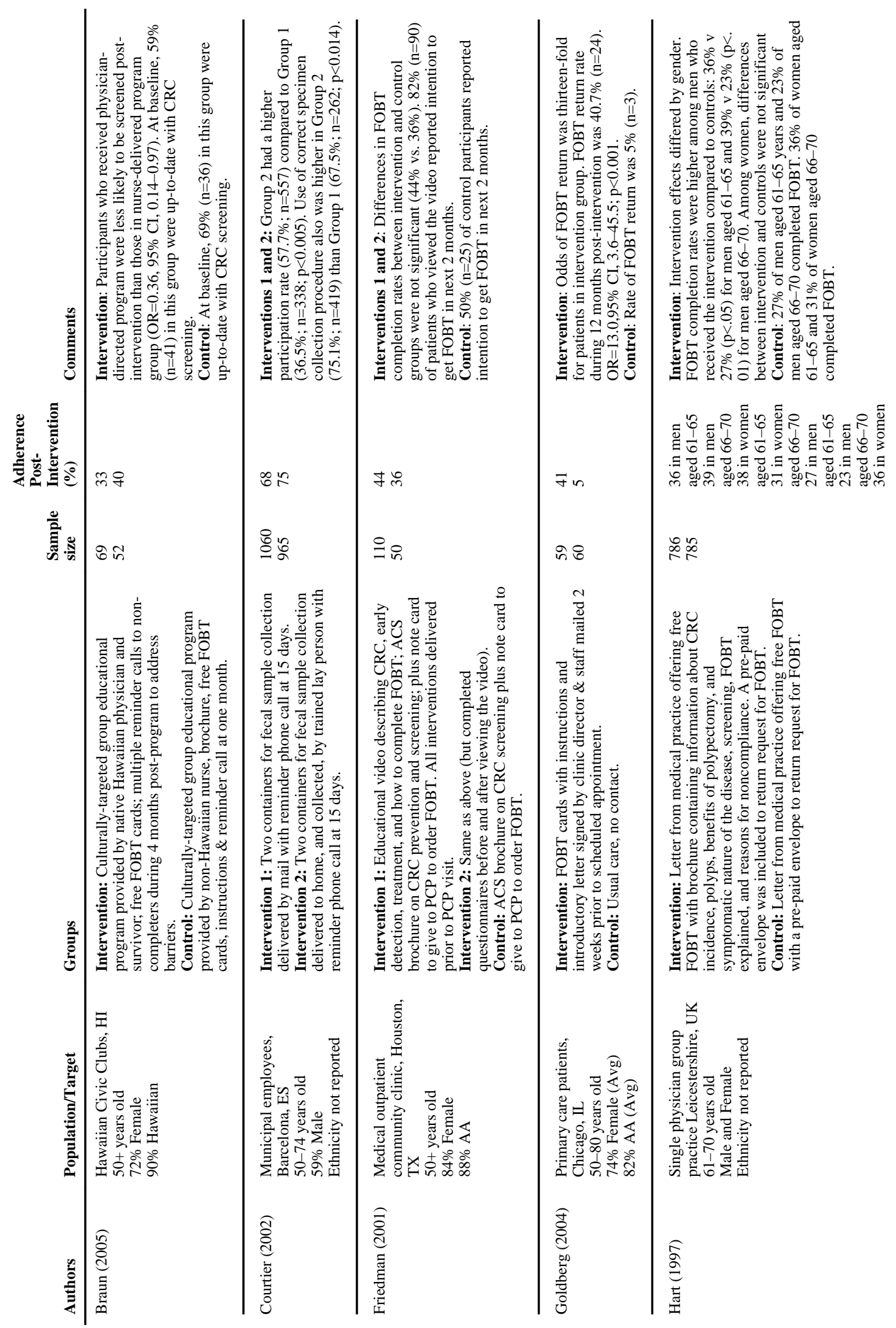

Nurs Outlook. Author manuscript; available in PMC 2013 July 01. 


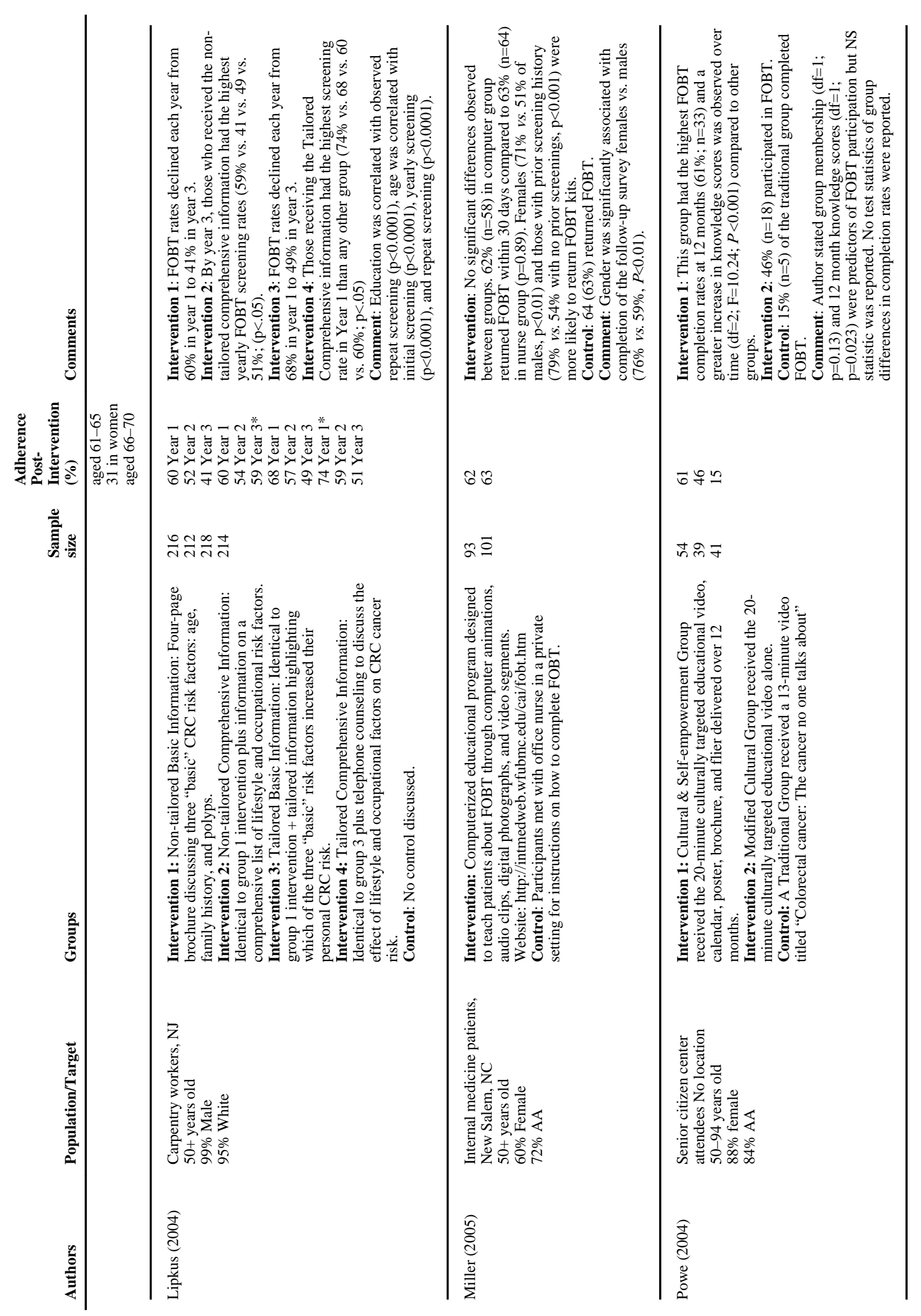

Nurs Outlook. Author manuscript; available in PMC 2013 July 01. 


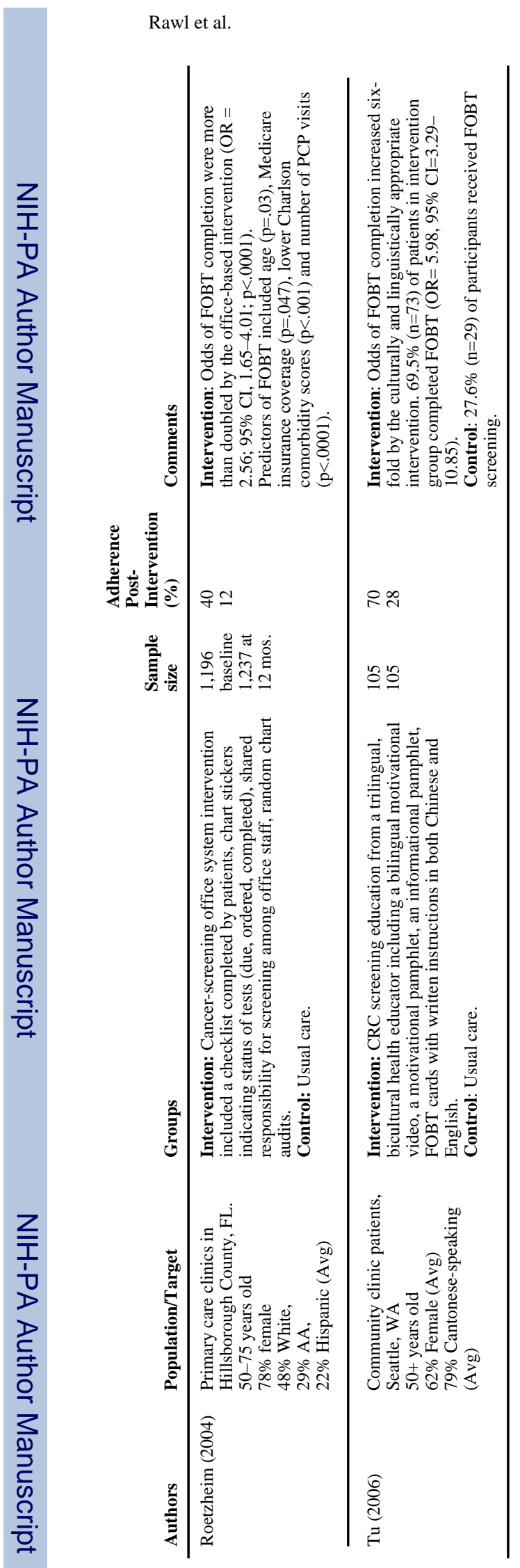

Page 16

Nurs Outlook. Author manuscript; available in PMC 2013 July 01. 


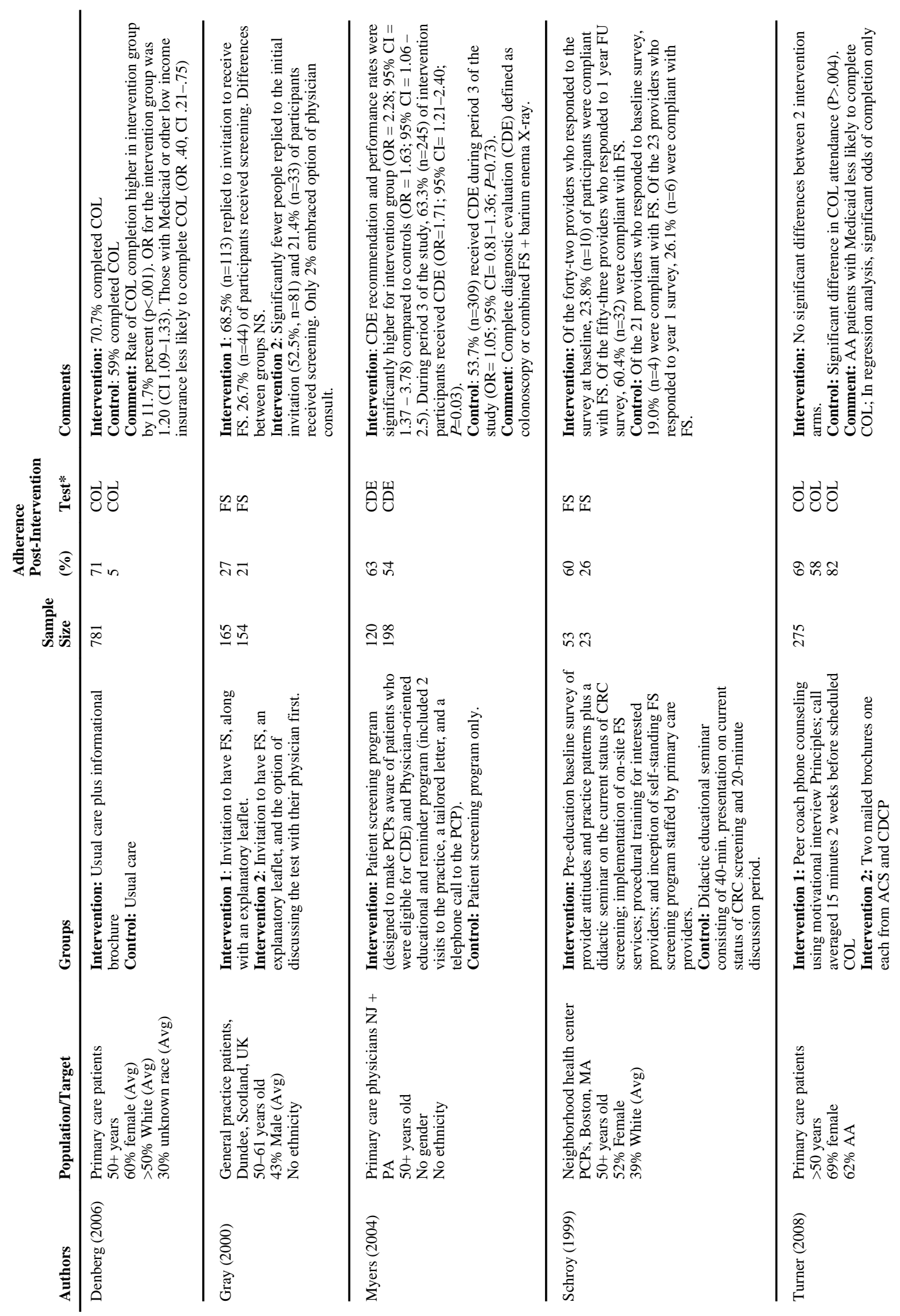

Nurs Outlook. Author manuscript; available in PMC 2013 July 01. 


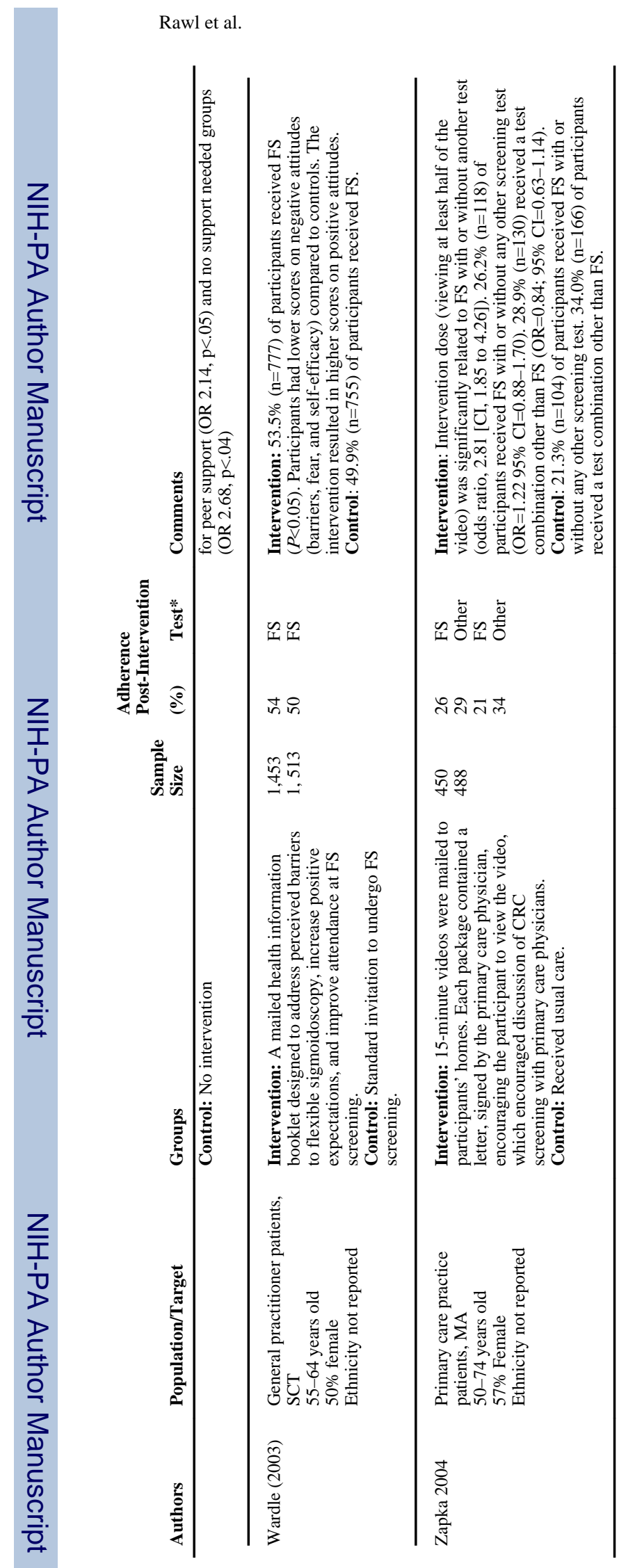

Page 18 


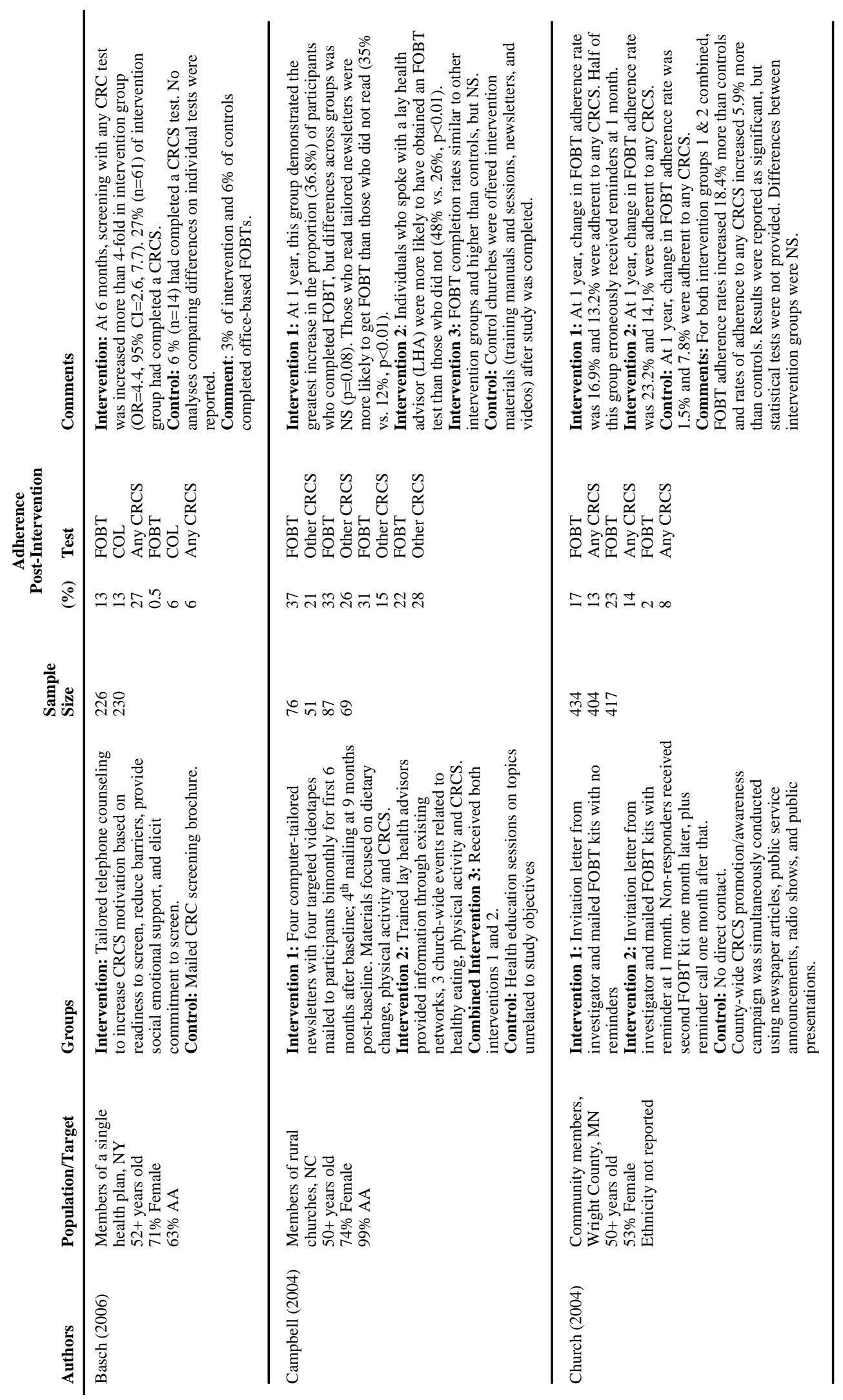

Nurs Outlook. Author manuscript; available in PMC 2013 July 01. 


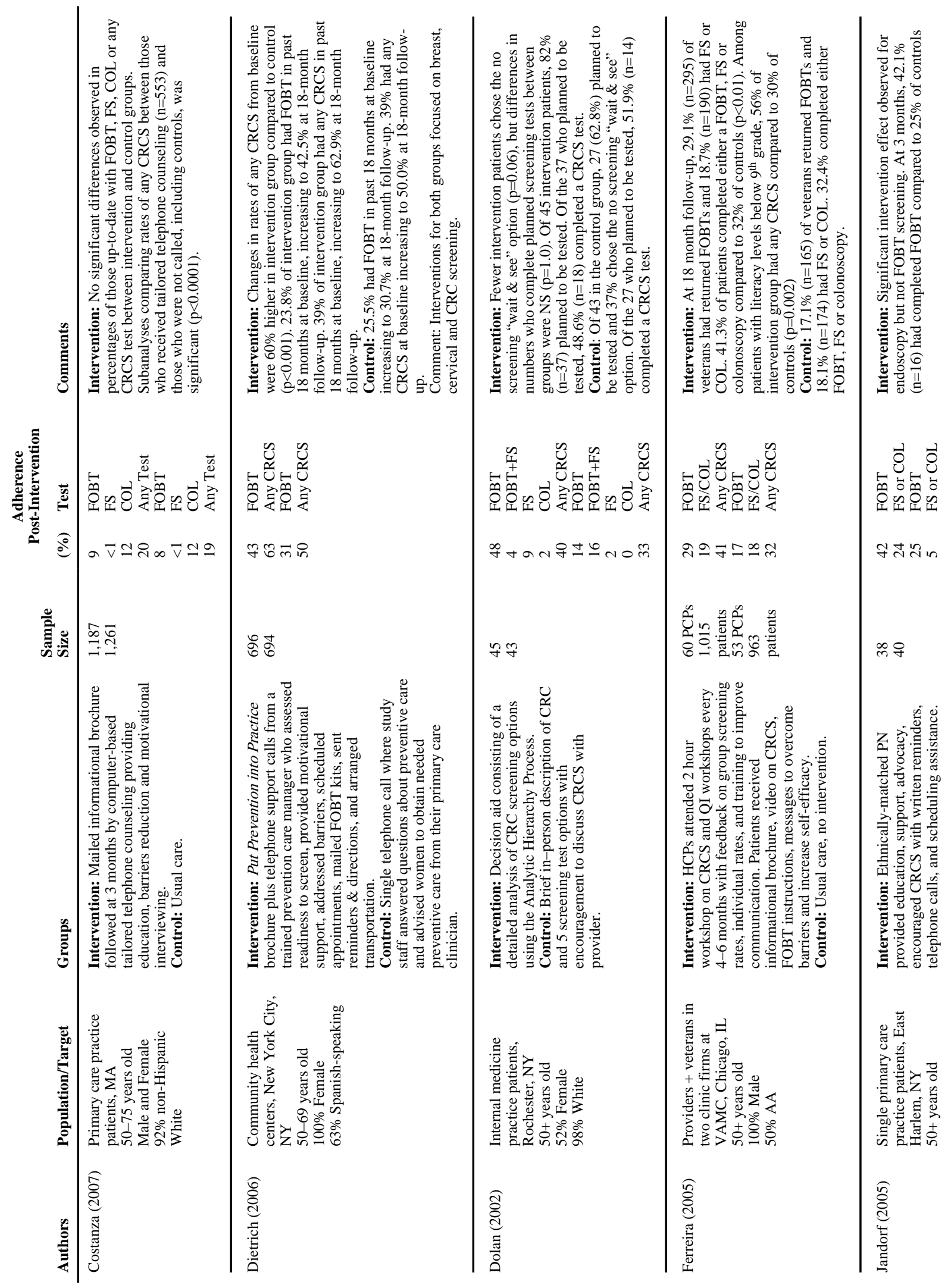

Nurs Outlook. Author manuscript; available in PMC 2013 July 01. 


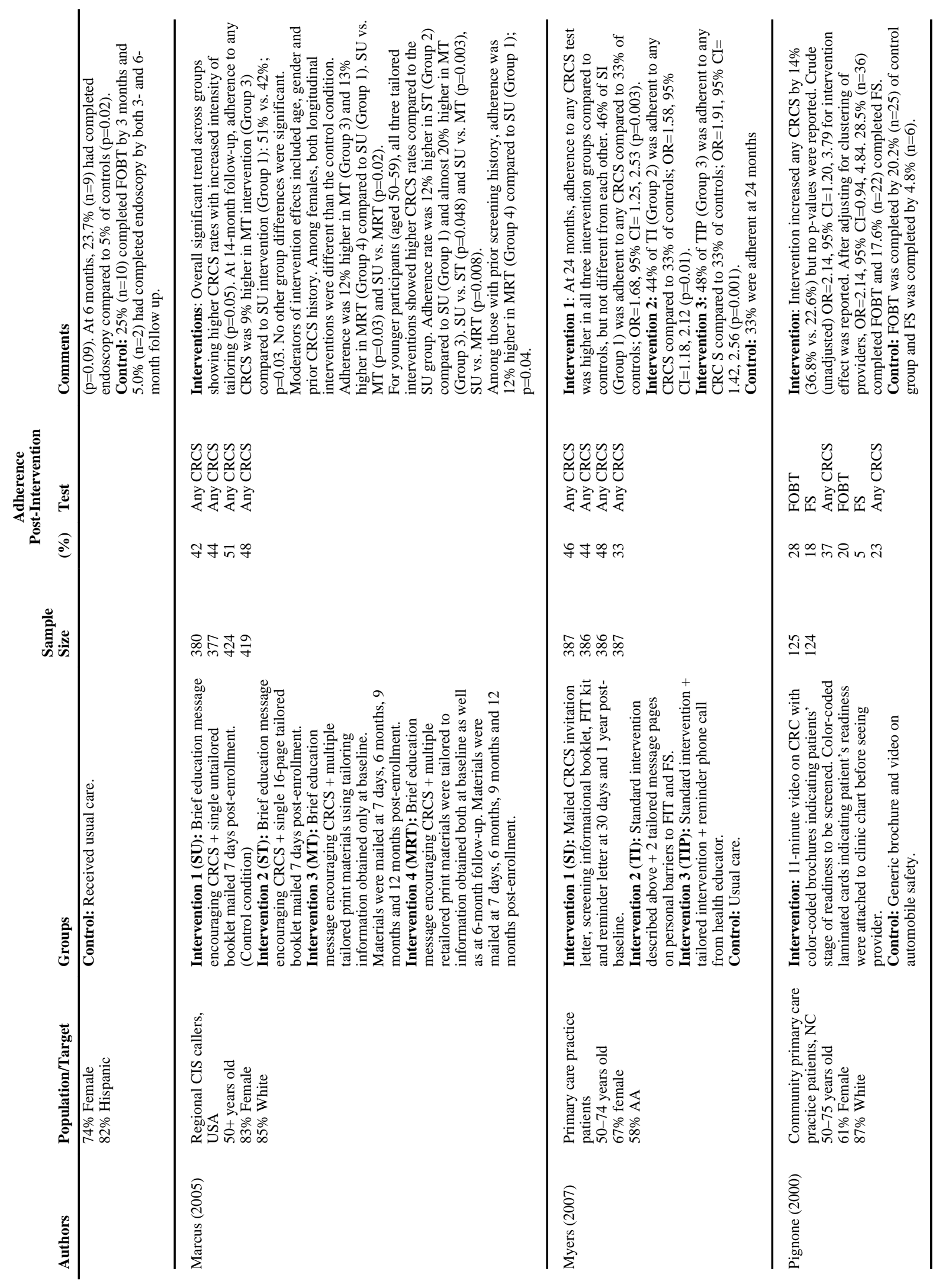

Nurs Outlook. Author manuscript; available in PMC 2013 July 01. 


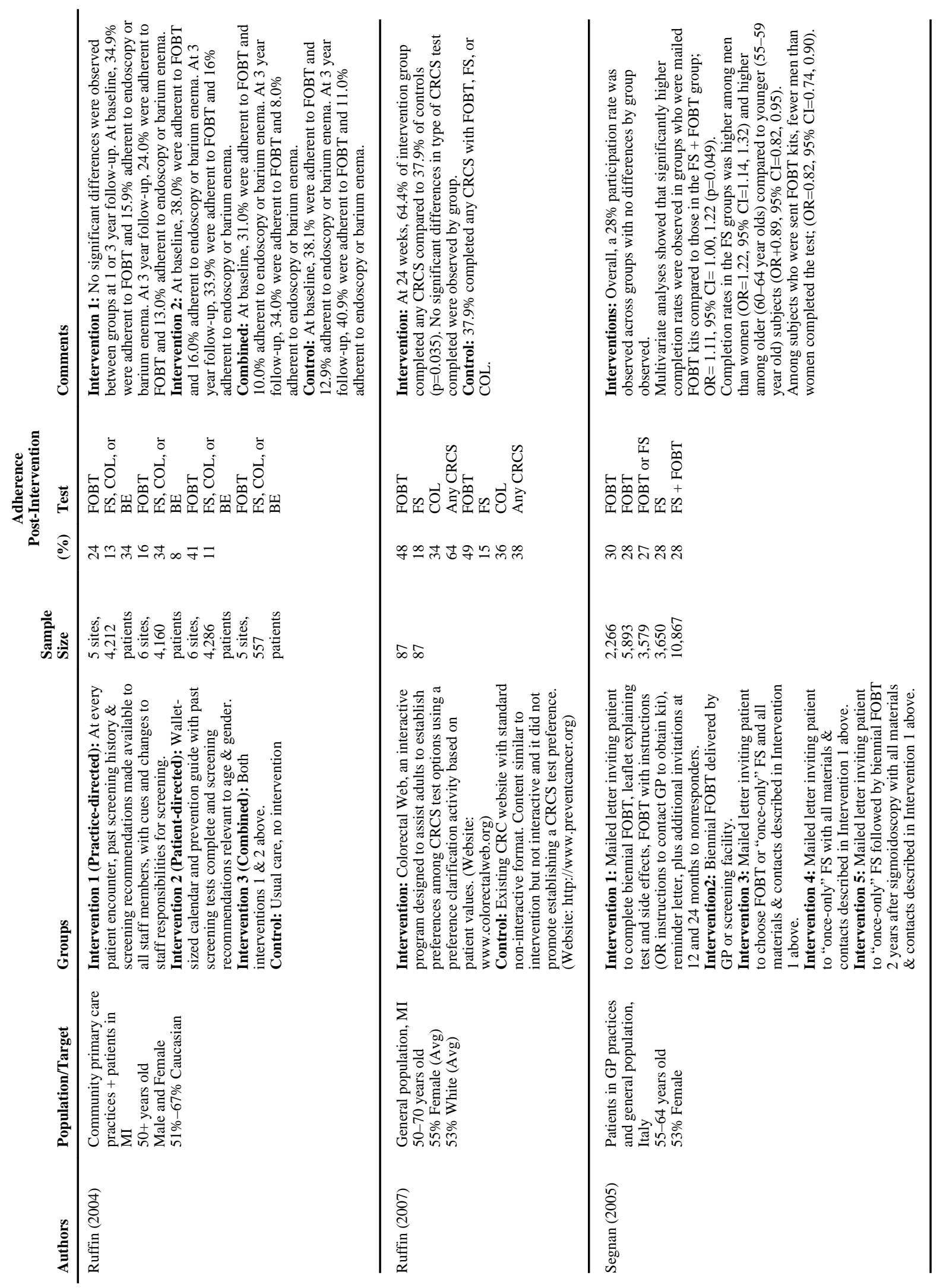




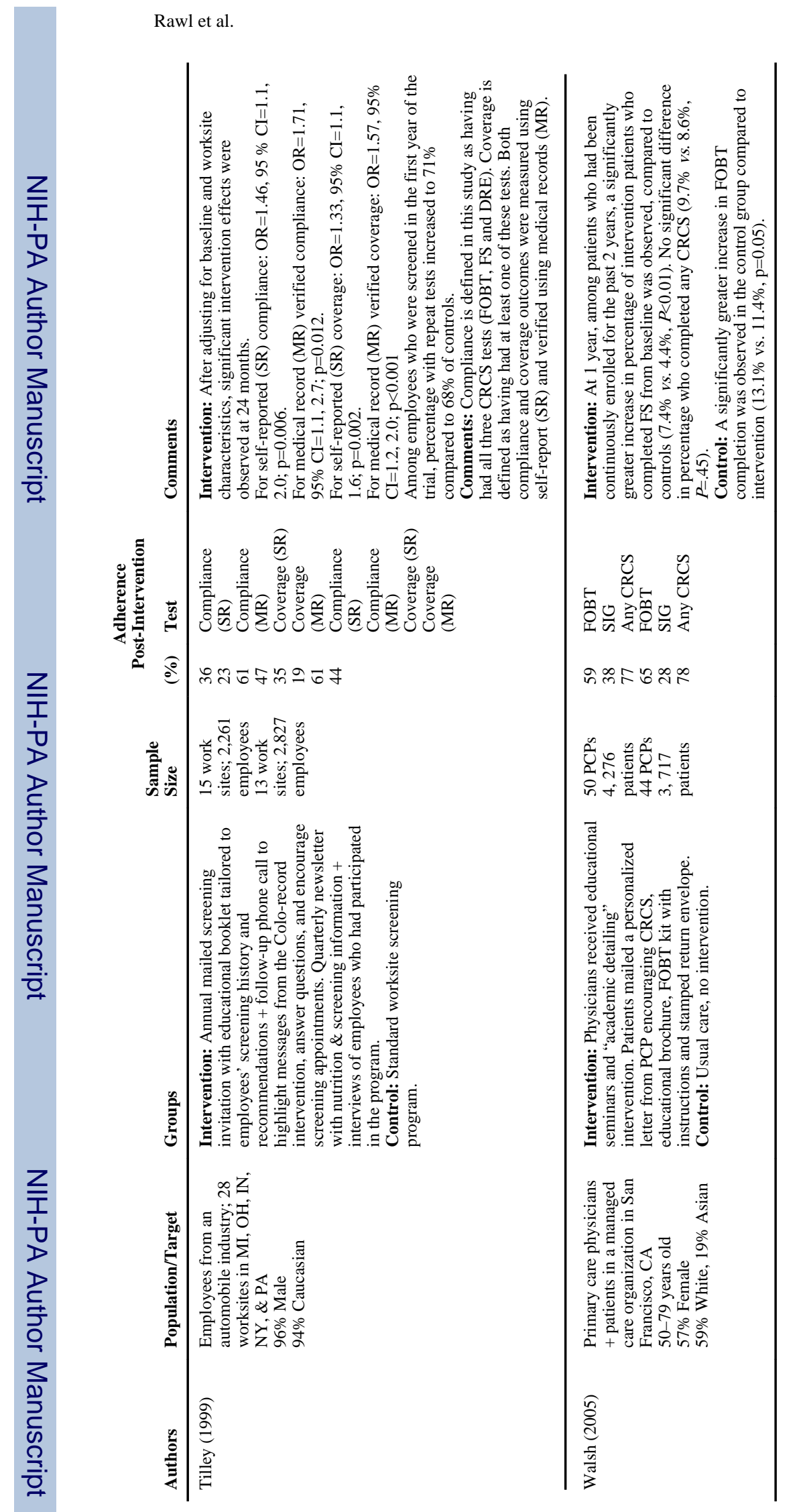

Nurs Outlook. Author manuscript; available in PMC 2013 July 01. 
Table 5

FOBT Trials Meeting TREND Criteria

\begin{tabular}{|c|c|c|}
\hline Content & Criterion Description & $\begin{array}{l}\text { FOBT Studies } \\
\text { Meeting Criteria }\end{array}$ \\
\hline Design & Study design stated $(\mathrm{n}=10)$ & $12-20,53$ \\
\hline Objectives & Specific objectives/aims/goals or hypotheses stated $(n=10)$ & $12-20,53$ \\
\hline Outcome & Outcome variables defined $(n=10)$ & $12-20,53$ \\
\hline Theoretical framework & Conceptual framework or theories used in designing interventions $(n=4)$ & $12,15-17$ \\
\hline \multirow[t]{5}{*}{ Methods Participants } & $\begin{array}{l}\text { Eligibility criteria for participants, including criteria at different levels in recruitment/ } \\
\text { sampling plan (e.g., cities,/clinics, subjects) }(\mathrm{n}=10)\end{array}$ & $12-20,53$ \\
\hline & $\begin{array}{l}\text { Methods of recruitment (e.g., referral, self-selection), including the sampling method if a } \\
\text { systematic sampling plan was implemented }(n=9)\end{array}$ & $12-14,16-20,53$ \\
\hline & Recruitment setting ( $\mathrm{n}=9)$ & $12,13,15-20,53$ \\
\hline & Settings and locations where the data were collected $(n=9)$ & $12-19,53$ \\
\hline & Sample description/characteristics includes flow of participants through the study $(n=6)$ & $12,13,15-17,53$ \\
\hline \multirow[t]{7}{*}{ Interventions } & $\begin{array}{l}\text { Details of the interventions intended for each study/condition and how and when they were } \\
\text { actually administered, specifically including: Content: what was given? }(\mathrm{n}=10)\end{array}$ & $12-19,53,54$ \\
\hline & Delivery method: how was the content given? $(\mathrm{n}=9)$ & $12-17,19,53,54$ \\
\hline & Unit of delivery: how were subjects grouped during delivery? $(\mathrm{n}=8)$ & $12-19$ \\
\hline & Deliverer: who delivered the intervention? $(n=9)$ & $12,13,15-20,53$ \\
\hline & Setting: where was the intervention delivered? $(\mathrm{n}=10)$ & $12-20,53$ \\
\hline & $\begin{array}{l}\text { Exposure quantity and duration: how many sessions or episodes or events were intended to } \\
\text { be delivered? Time span: how long was it intended to take to deliver the intervention to each } \\
\text { unit? }(n=7)\end{array}$ & $12-16,19,20$ \\
\hline & Activities to increase compliance or adherence (e.g., incentives) $(n=0)$ & $\begin{array}{l}\text { No studies met this } \\
\text { criterion }\end{array}$ \\
\hline Results & Study results include negative findings $(n=10)$ & $12-20,53$ \\
\hline Limitations & Limitations acknowledged $(\mathrm{n}=7)$ & $12-15,17,18,53$ \\
\hline Generalizability & $\begin{array}{l}\text { Generalizability (external validity) of the trial findings is described (for example, taking into } \\
\text { account the study population, the characteristics of the intervention, length of follow-up, } \\
\text { incentives, compliance rates, specific sites/settings involved in the study, and other } \\
\text { contextual issues) }(n=4)\end{array}$ & $13,15,16,53$ \\
\hline Overall evidence & $\begin{array}{l}\text { General interpretation of the results in the context of current evidence and current theory } \\
(\mathrm{n}=6)\end{array}$ & $12,13,16-18,53$ \\
\hline
\end{tabular}


Table 6

Endoscopy Screening Trials Meeting TREND Criteria

\begin{tabular}{|c|c|c|}
\hline Content & Criterion Description & $\begin{array}{l}\text { Endoscopy Studies Meeting } \\
\text { Criteria }\end{array}$ \\
\hline Design & Study design stated $(n=5)$ & $24,25,27-29$ \\
\hline Objectives & Specific objectives/aims/goals or hypotheses stated* $(n=5)$ & $23-26,28$ \\
\hline Outcome & Outcome variables defined $(n=7)$ & $23-29$ \\
\hline Theoretical framework & Conceptual framework or theories used in designing interventions $(n=4)$ & $24,26-28$ \\
\hline \multirow[t]{5}{*}{ Methods Participants } & $\begin{array}{l}\text { Eligibility criteria for participants, including criteria at different levels in } \\
\text { recruitment/sampling plan (e.g., cities,/clinics, subjects) }(n=6)\end{array}$ & $23-28$ \\
\hline & $\begin{array}{l}\text { Methods of recruitment (e.g., referral, self-selection), including the sampling } \\
\text { method if a systematic sampling plan was implemented }(n=6)\end{array}$ & $23-28$ \\
\hline & Recruitment setting $(n=6)$ & $23-28$ \\
\hline & Settings and locations where the data were collected $(n=6)$ & $23-28$ \\
\hline & $\begin{array}{l}\text { Sample description/characteristics includes flow of participants through the study } \\
(\mathrm{n}=4)\end{array}$ & $24,25,27,28$ \\
\hline \multirow[t]{7}{*}{ Interventions } & $\begin{array}{l}\text { Details of the interventions intended for each study/condition and how and when } \\
\text { they were actually administered, specifically including: Content: what was given? } \\
(\mathrm{n}=7)\end{array}$ & $23-29$ \\
\hline & Delivery method: how was the content given? $(n=6)$ & $23-28$ \\
\hline & Unit of delivery: how were subjects grouped during delivery? $(n=6)$ & $23-28$ \\
\hline & Deliverer: who delivered the intervention? $(n=5)$ & $24-28$ \\
\hline & Setting: where was the intervention delivered? $(n=6)$ & $23-28$ \\
\hline & $\begin{array}{l}\text { Exposure quantity and duration: how many sessions or episodes or events were } \\
\text { intended to be delivered? Time span: how long was it intended to take to deliver } \\
\text { the intervention to each unit? }(\mathrm{n}=7)\end{array}$ & $23-29$ \\
\hline & Activities to increase compliance or adherence (e.g., incentives) $(n=0)$ & No studies met criterion \\
\hline Results & Study results include negative findings $(n=6)$ & $23,25-29$ \\
\hline Limitations & Limitations acknowledged $(n=6)$ & $23-28$ \\
\hline Generalizability & $\begin{array}{l}\text { Generalizability (external validity) of the trial findings is described (for example, } \\
\text { taking into account the study population, the characteristics of the intervention, } \\
\text { length of follow-up, incentives, compliance rates, specific sites/settings involved } \\
\text { in the study, and other contextual issues) }(n=5)\end{array}$ & $24-28$ \\
\hline Overall evidence & $\begin{array}{l}\text { General interpretation of the results in the context of current evidence and current } \\
\text { theory }(n=6)\end{array}$ & $23-28$ \\
\hline
\end{tabular}


Table 7

Trials Promoting Any CRC Screening Test Meeting TREND Criteria

\begin{tabular}{|c|c|c|}
\hline Content & Criterion Description & $\begin{array}{l}\text { Any CRC Screening } \\
\text { Studies } \\
\text { Meeting Criteria }\end{array}$ \\
\hline Design & Study design stated $(\mathrm{n}=15)$ & $30-37,39-45$ \\
\hline Objectives & Specific objectives/aims/goals or hypotheses stated* $(n=14)$ & $30-35,37-41,43-45$ \\
\hline Outcome & Outcome variables defined $(n=16)$ & $30-45$ \\
\hline Theoretical framework & Conceptual framework or theories used in designing interventions $(n=10)$ & $30-34,39,40,42-44$ \\
\hline \multirow[t]{5}{*}{ Methods Participants } & $\begin{array}{l}\text { Eligibility criteria for participants, including criteria at different levels in recruitment/ } \\
\text { sampling plan (e.g., cities,/clinics, subjects) }(n=12)\end{array}$ & $30-34,36,37,39-45$ \\
\hline & $\begin{array}{l}\text { Methods of recruitment (e.g., referral, self-selection), including the sampling method if } \\
\text { a systematic sampling plan was implemented }(n=14)\end{array}$ & $30-37,40-45$ \\
\hline & Recruitment setting $(\mathrm{n}=14)$ & $30-37,40-45$ \\
\hline & Settings and locations where the data were collected $(n=16)$ & $30-45$ \\
\hline & $\begin{array}{l}\text { Sample description/characteristics includes flow of participants through the study } \\
(\mathrm{n}=15)\end{array}$ & $30-35,37-45$ \\
\hline \multirow[t]{7}{*}{ Interventions } & $\begin{array}{l}\text { Details of the interventions intended for each study/condition and how and when they } \\
\text { were actually administered, specifically including: Content: what was given? }(n=13)\end{array}$ & $30-38,40-45$ \\
\hline & Delivery method: how was the content given? $(\mathrm{n}=16)$ & $30-45$ \\
\hline & Unit of delivery: how were subjects grouped during delivery? $(n=16)$ & $30-45$ \\
\hline & Deliverer: who delivered the intervention? $(\mathrm{n}=12)$ & $30-35,38,40-42,44,45$ \\
\hline & Setting: where was the intervention delivered? $(n=15)$ & $30-35,37-45$ \\
\hline & $\begin{array}{l}\text { Exposure quantity and duration: how many sessions or episodes or events were } \\
\text { intended to be delivered? Time span: how long was it intended to take to deliver the } \\
\text { intervention to each unit? }(\mathrm{n}=13)\end{array}$ & $30-35,37,38,40-42,44,45$ \\
\hline & Activities to increase compliance or adherence (e.g., incentives) $(n=5)$ & $32,39,43-45$ \\
\hline Results & Study results include negative findings $(n=13)$ & $30,32-36,38-43,45$ \\
\hline Limitations & Limitations acknowledged $(\mathrm{n}=13)$ & $30-34,36-38,40,42-45$ \\
\hline Generalizability & $\begin{array}{l}\text { Generalizability (external validity) of the trial findings is described (for example, } \\
\text { taking into account the study population, the characteristics of the intervention, length } \\
\text { of follow-up, incentives, compliance rates, specific sites/settings involved in the study, } \\
\text { and other contextual issues) }(n=14)\end{array}$ & $30-36,38,40-45$ \\
\hline Overall evidence & $\begin{array}{l}\text { General interpretation of the results in the context of current evidence and current } \\
\text { theory }(n=13)\end{array}$ & $30-38,40-42,45$ \\
\hline
\end{tabular}

